\title{
La criptosporidiosis en la región andina de Colombia: seroprevalencia y reconocimiento de antígenos
}

\author{
Claudia Vergara Castiblanco, ${ }^{1}$ Sonia Santos Núñez, ${ }^{1}$ \\ Francisco Freire Santos ${ }^{1}$ y Elvira Ares Mazás ${ }^{2}$
}

RESUMEN El objetivo de este estudio fue investigar, por primera vez, la seroprevalencia de la criptosporidiosis en habitantes urbanos y rurales de distintos departamentos de la región andina de Colombia. Se estudió también el reconocimiento de antígenos de Cryptosporidium parvum por los sueros. Entre junio de 1996 y octubre de 1998 se recogieron 1778 muestras séricas de personas seleccionadas mediante un muestreo "de conveniencia". La detección de anticuerpos (IgM, IgA e IgG) anti-C. parvum se realizó mediante la técnica de ELISA y el reconocimiento de antígenos, por una técnica de inmunoelectrotransferencia. Se halló una prevalencia de $83,3 \%$, mientras que los porcentajes de anticuerpos fueron $72,2 \%$ de IgM; $27,7 \%$ de $\operatorname{IgA}$ y $27,6 \%$ de IgG. Los porcentajes de seropositividad más altos se obtuvieron en mujeres, menores de 30 años de edad y personas de procedencia rural. Se observó que la seroprevalencia de IgM disminuye a medida que aumenta la edad, mientras que las de IgG e IgA aumentan al par que la edad. Estos tres isotipos reconocieron con mayor frecuencia los antígenos de 51 a $69 \mathrm{kDa}$, que pueden considerarse inmunodominantes. Se destacó la inmunorreactividad de IgM e IgA a fracciones proteinicas de 12 a $14 \mathrm{kDa}$ y de 42 a $48 \mathrm{kDa}$, respectivamente, lo que podría indicar exposición al parásito. Estos resultados parecen indicar que la criptosporidiosis es endémica en esa región de Colombia, por lo que es posible atribuir muchos casos de síndrome diarreico a C. parvum.

El protozoo coccidio Cryptosporidium parvum es un parásito de distribución mundial que puede ocasionar graves infecciones diarreicas tanto en los seres humanos como en los animales. Entre estos últimos, afecta principalmente a los rumiantes y causa pérdidas econó-

\footnotetext{
1 Universidad de Santiago de Compostela, España.

2 Toda la correspondencia debe enviarse a esta autora, a la siguiente dirección: Universidad de Santiago de Compostela, Facultad de Farmacia, Departamento de Microbiología y Parasitología, Laboratorio de Parasitología. Av.Vigo s/n, 15706, Santiago de Compostela, La Coruña, España. Fax: 34981 593316. Correo electrónico: mpeares@usc.es
}

micas considerables debido a la alta morbilidad que ocasiona y la consecuente reducción de la producción cárnica y lechera (1). En las personas con función inmunitaria competente, la criptosporidiosis se presenta como un cuadro diarreico agudo, pero autolimitado, que se resuelve espontáneamente. En las personas con función inmunitaria comprometida, el síndrome diarreico es grave, tiende a la cronicidad y puede poner en peligro la vida del paciente (2).

Independientemente de su causa, el síndrome diarreico es uno de los más im- portantes problemas de salud pública en América Latina, debido a las altas tasas de morbilidad y mortalidad que ocasiona en la población infantil. Esta población se considera en alto riesgo de padecer criptosporidiosis $(2,3)$.

En Suramérica, Colombia ocupa el cuarto lugar en extensión geográfica y el tercero en tamaño de la población. Este país comprende cinco grandes regiones naturales: la del Caribe, la del Pacífico, la Orinoquia, la Amazonia y la región andina. El sistema montañoso de esta última representa aproximadamente la tercera parte del territorio na- 
cional en donde se concentra $70 \%$ de la población, mientras que el resto vive en las regiones del Orinoco, las selvas del Amazonas y del Pacífico, y la región semidesértica de la Guajira (4).

Teniendo en cuenta los escasos datos epidemiológicos sobre la criptosporidiosis existentes en Colombia así como la importancia de C. parvum en la etiología del síndrome diarreico, el objetivo de este trabajo fue realizar la primera investigación serológica de la prevalencia de criptosporidiosis en poblaciones urbanas y rurales de distintos departamentos de la zona andina de Colombia. Se estudió asimismo el reconocimiento de antígenos de $C$. parvum por los sueros de los individuos de la muestra y la presencia de anticuerpos específicos (inmunoglobulinas A, M y G) contra los antígenos de C. parvum. Para ello se emplearon el ensayo inmunoenzimático ELISA y la técnica de inmunoelectrotransferencia (Western blot).

\section{MATERIALES Y MÉTODOS}

\section{Población de estudio}

Durante el período de junio de 1996 a octubre de 1998, se recogieron muestras séricas de 1778 individuos procedentes de las cuatro capitales de departamentos de la zona andina: Cali, Medellín, Bucaramanga y Santa Fe de Bogotá, así como también de habitantes de los municipios rurales cercanos al área metropolitana de Medellín (figura 1).

La selección de los sueros estuvo supeditada a la colaboración desinteresada de las autoridades sanitarias de cada departamento, por lo que el muestreo realizado es lo que se denomina, en términos epidemiológicos, "de conveniencia". Sin embargo, según la opinión de epidemiólogos consultados, no hay motivos para suponer que haya sesgo en las muestras analizadas (A. Figueiras Guzmán, Facultad de Medicina de la Universidad de Santiago de Compostela, comunicación personal, 1999). En algunos casos se dispuso de información con respecto al sexo (604 hombres y 928 mujeres), la edad (214 personas de 14 años o menos; 369 entre los 15 y 30 años, y 932 de 30 años o más) y la procedencia geográfica (131 de zonas rurales y 1470 de zonas urbanas). En ningún caso se obtuvieron datos coprológicos sobre la presencia de oocistos de Cryptosporidium sp. en esos individuos. Todas las muestras séricas se almacenaron a $-20{ }^{\circ} \mathrm{C}$ hasta su empleo.

\section{Concentración y purificación de oocistos}

El material antigénico utilizado para detectar los anticuerpos específi- cos y el reconocimiento de antígenos por los sueros incluidos en este estudio consistió en oocistos de C. paroum obtenidos de heces de terneros de raza frisona, de 6 a 15 días de edad, naturalmente infectados con el parásito. Los oocistos se concentraron y purificaron de acuerdo con un protocolo ya establecido (5), que se describe brevemente a continuación. Las heces se recogieron directamente del recto de los animales, se maceraron en tampón fosfato salino (PBS) con molaridad de 0,04 y $\mathrm{pH}$ de 7,2 y se filtraron a través de mallas con poros de $45 \mu \mathrm{m}$. Seguidamente se aplicó una técnica

\section{FIGURA 1. Mapa de Colombia. Regiones naturales de Colombia}

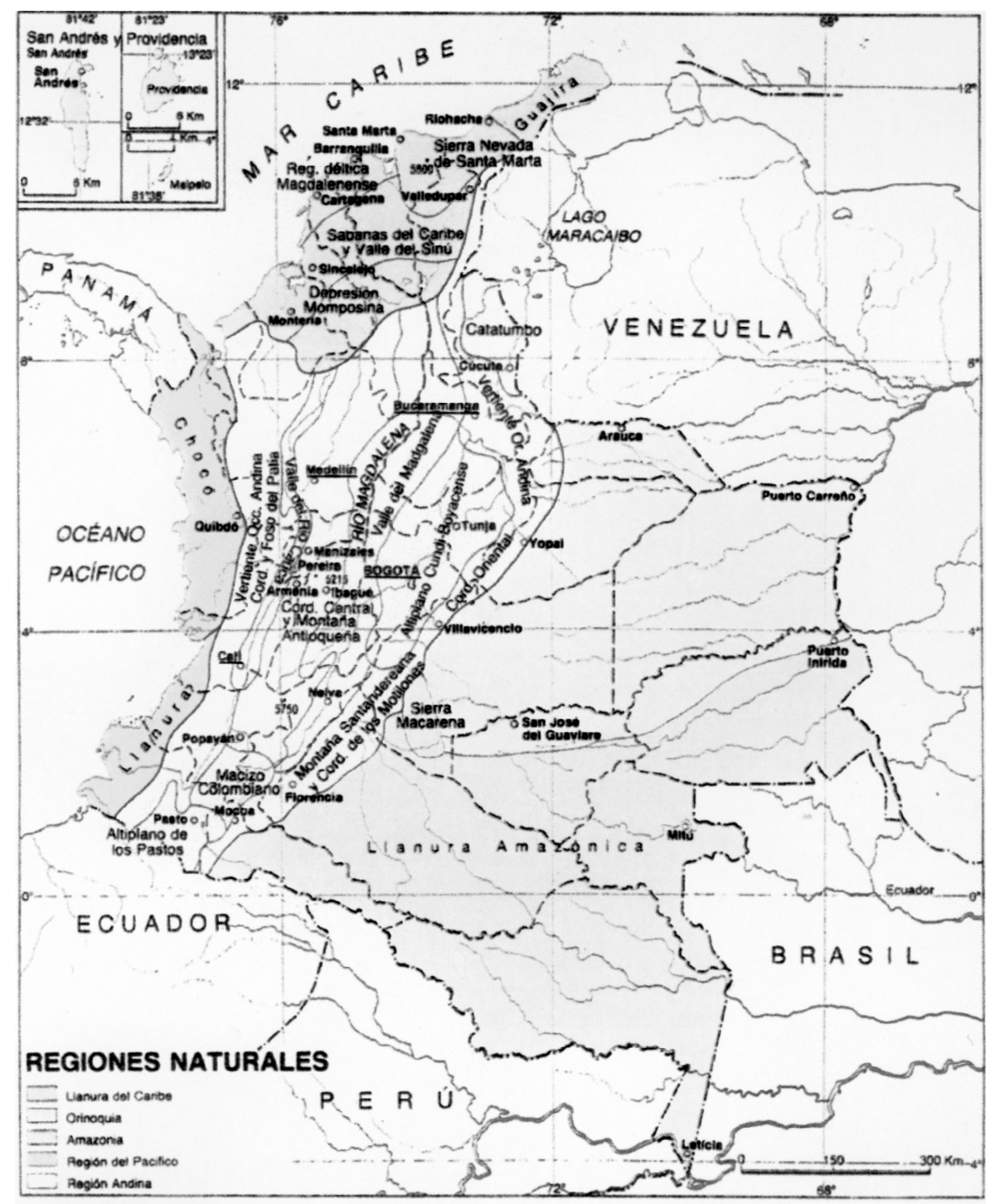


de concentración difásica con PBS y éter etílico mezclando dos partes de la suspensión de heces con una parte del éter etílico para eliminar restos lipídicos. La mezcla se agitó vigorosamente y se centrifugó a $1250 \mathrm{~g} \mathrm{du}$ rante 5 minutos. El procedimiento se repitió hasta haber extraído totalmente los restos lipídicos. El sedimento obtenido se resuspendió en $1 \mathrm{~mL}$ de PBS para posterior purificación empleando gradientes discontinuos de Percoll con densidades de 1,13; 1,09; 1,$05 ;$ y $1,01 \mathrm{~g} / \mathrm{mL}$. Los gradientes se centrifugaron a $650 \mathrm{~g}$ y $4{ }^{\circ} \mathrm{C}$ durante 15 minutos y se recuperó la banda rica en oocistos obtenida entre las densidades 1,05 y $1,09 \mathrm{~g} / \mathrm{mL}$. Por último, se realizaron tres lavados con PBS para eliminar el exceso de Percoll. El recuento de oocistos se realizó en hemocitómetro empleando como colorante una solución acuosa de verde malaquita a $0,16 \%$.

\section{Investigación de anticuerpos específicos}

Como material antigénico se emplearon oocistos intactos sometidos a un proceso de sonicación (Branson Sonifier 450, Danbury, CT) durante 1 hora. La concentración proteínica se determinó por el método de Lowry modificado (6) y la prueba de ELISA se realizó de acuerdo con la técnica descrita previamente por Lorenzo (7), recubriendo cada uno de los pocillos de placas de poliestireno (Nunc, Roskilde, Dinamarca) con $100 \mu \mathrm{L}$ de tampón carbonato con pH 9,6 que contenía 0,6 $\mu \mathrm{g}$ de las proteínas del parásito. Para cada inmunoglobulina se estableció un punto de corte conservador, determinando el valor medio de las absorbancias de 130 muestras séricas de donantes de sangre colombianos, más o menos 2 desviaciones estándar (DE). Los valores fuera de este intervalo se eliminaron y se determinó una nueva media. Los sueros con absorbancias iguales o superiores a este nuevo valor se consideraron positivos. Las comparaciones estadísticas entre los grupos establecidos se basaron en la prueba de ji al cuadrado $\left(\chi^{2}\right)(8)$ y los valores iguales o menores de $P<0,05$ se consideraron estadísticamente significativos.

\section{Reconocimiento de antígenos de C. paroum}

El antígeno empleado para llevar a cabo la electroforesis en geles de poliacrilamida (fracción concentradora a $5 \%$ y separadora a 15\%) consistió en un extracto soluble de oocistos intactos de C. parvum $\left(2 \times 10^{6}\right.$ oocistos a 10 $\mu \mathrm{L}$ por pocillo) obtenido por calentamiento a $100{ }^{\circ} \mathrm{C}$, durante 5 minutos, de una mezcla en proporción de 1:1 de oocistos intactos del parásito y tampón de muestra que contenía 2- $\beta$ mercaptoetanol (condiciones reductoras). El sobrenadante obtenido tras centrifugación se empleó como antígeno. Las proteínas separadas por electroforesis se transfirieron desde los geles a membranas de nitrocelulosa con poros de 0,45 $\mu \mathrm{m}$ (Bio-Rad, 162-0115).

El reconocimiento de antígenos por las inmunoglobulinas presentes en los sueros se realizó mediante la aplicación de una técnica de inmunocoloración que emplea anti-inmunoglobulinas humanas de las clases A, M y G marcadas con biotina (Sigma B-5893, $B-1265$ y $B-1140$, respectivamente), un complejo enzimático de estreptavidina y fosfatasa alcalina (Bio-Rad 170-3554) y, como sustrato cromógeno, el 5-bromo-4-cloro-3-indol fosfato/nitroazul de tetrazolio (Sigma B5655). Los pesos moleculares de las fracciones proteínicas reconocidas por los sueros analizados se calcularon mediante comparación de su movilidad relativa con el patrón de peso molecular unido a la biotina (Bio-Rad, 161-0306).

Para estudiar el reconocimiento antigénico de las proteínas oocísticas de C. parvum por las inmunoglobinas $\mathrm{M}$, A y $\mathrm{G}$, se seleccionaron al azar muestras séricas en las que se investigó previamente la presencia de esos anticuerpos mediante la técnica de ELISA. Se utilizaron 285, 276 y 294 sueros, respectivamente, para determinar el reconocimiento de los antígenos por parte de la IgM, la IgA y la IgG.

\section{RESULTADOS}

\section{Investigación de inmunoglobulinas específicas frente a $C$. paroum}

El análisis de los 1778 sueros reveló la presencia de anticuerpos específicos (IgA, IgM e IgG) en 1482 muestras, lo que representa una prevalencia muestral de $83,3 \%$. La proporción más elevada de seropositividad correspondió a la IgM, con un valor de 72,2\% (1 284 sueros), mientras que los de la IgA y la IgG fueron similares: $27,7 \%$ (492 sueros) y $27,6 \%$ (491 sueros), respectivamente.

Teniendo en cuenta el sexo de los individuos analizados, se observó que las prevalencias fueron significativamente mayores $(P<0,001)$ en las mujeres $(83,2 \%)$ que en los hombres $(71,2 \%)$. Los porcentajes de seropositividad obtenidos para la $\operatorname{IgM}(P<0,001)$, la combinación de M y A $(P<0,01)$ y la combinación de $\mathrm{M}$ y $\mathrm{G}(P<0,05)$ fueron significativamente más elevados en las mujeres que en los hombres: $77,8 \%$ frente a $58,3 \%$; $13,9 \%$ frente a $8,8 \%$; y $15,5 \%$ frente a $11,2 \%$ respectivamente. Sin embargo, los porcentajes de seropositividad a la $\operatorname{IgG}(P<0,001)$ y la coexistencia de $\operatorname{IgG}$ e IgA $(P<0,05)$ fueron más elevados en la población masculina que en la femenina: $28,3 \%$ frente a $19,2 \%$ y $2,8 \%$ frente a $1,2 \%$, respectivamente (figura 2 ).

En relación con la edad, se observaron valores de seroprevalencia más altos en la población menor de 30 años: 85,5\% en el grupo de 0-14 años; $87 \%$ en el de 15-30 años y 79,5\% en el mayor de 30 años. Los niveles de seropositividad a la $\operatorname{IgM}$ obtenidos descendieron notablemente $(P<0,001)$ según aumentaba la edad de los individuos analizados: $83,2 \%$; $79,7 \%$ y $64,6 \%$, respectivamente. Los mayores porcentajes de seropositividad a la IgA se detectaron en el grupo de edad mayor de 30 años $(33,8 \%)$ y se observó que la seroprevalencia de este isotipo aumentaba significativamente $(P<0,001)$ con la edad: $10,7 \%$ en el grupo de $0-14$ años y 20\% en el grupo de 15-30 años. La seroprevalencia de IgG fue mayor $(30,9 \%)$ en el grupo de edad intermedia, diferencia que fue significativa $(P<0,05)$ solamente cuando este valor 
FIGURA 2. Porcentajes de seropositividad a las inmunoglobulinas $M, A$ y $G$ según el sexo y la edad, en sueros de habitantes de la región andina de Colombia, 1996 a 1998

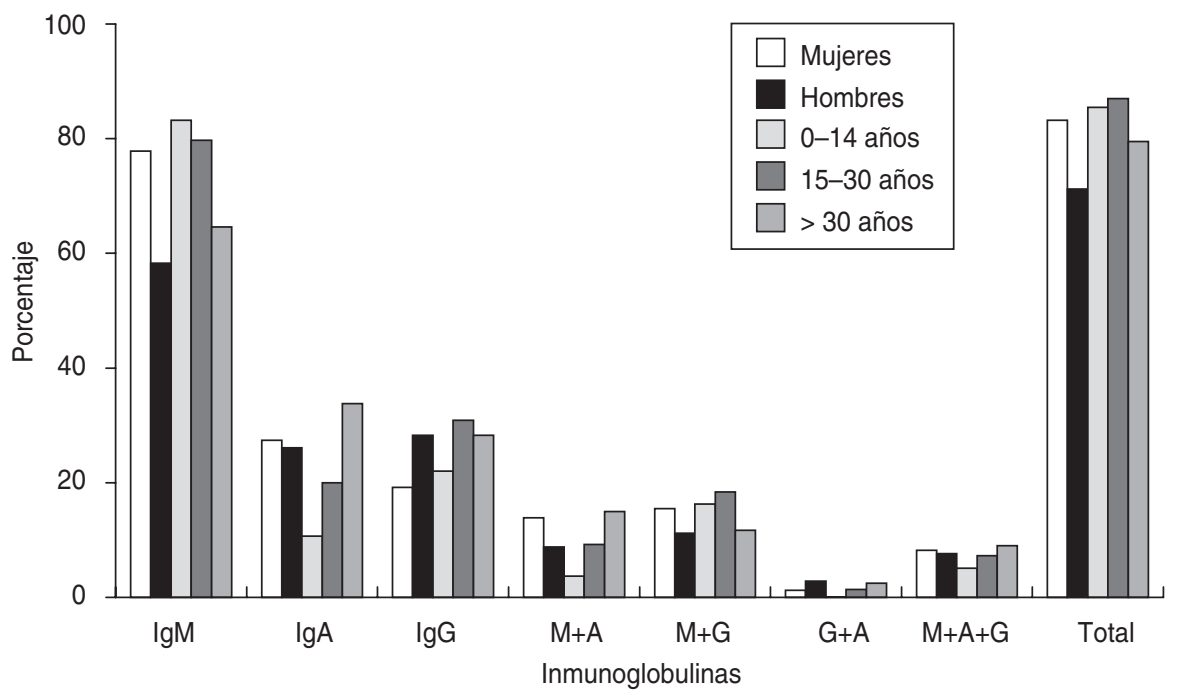

se comparó con el del grupo de 0-14 años (22\%), ya que en el grupo mayor de 30 años, el porcentaje de seropositividad fue muy parecido $(28,3 \%)$. Teniendo en cuenta la coexistencia de los distintos isotipos, cabe notar que los porcentajes obtenidos aumentaron también con la edad, excepto para la presencia conjunta de $\operatorname{IgM}$ e IgG, cuyos valores fueron más elevados $(18,4 \%)$ en el grupo de 15 a 30 años de edad (figura 2).

Con respecto a la procedencia rural o urbana de las personas cuyos sueros estudiamos, los valores de seroprevalencia fueron significativamente mayores $(P<0,001)$ en el medio rural que en el urbano: $95,4 \%$ frente a $82,4 \%$. Al analizar el total de datos obtenidos sobre cada inmunoglobulina, se observaron valores significativamente más elevados $(P<0,001)$ tanto de la IgM como de la IgA y la IgG en individuos procedentes del medio rural: $86,3 \%$ frente a $71,1 \% ; 48,9 \%$ frente a $26 \%$, y $39,7 \%$ frente a $26,7 \%$. Con respecto a las distintas combinaciones de inmunoglobulinas, no se observaron diferencias estadísticamente significativas (figura 3).

\section{Reconocimiento de antígenos}

Como indica el cuadro 1, la mayoría de los sueros reconocieron antígenos cuyos pesos moleculares aproximados correspondieron a fracciones proteíni-

FIGURA 3. Porcentajes de seropositividad a las inmunoglobulinas según la procedencia geográfica de los sueros, región andina de Colombia, 1996 a 1998

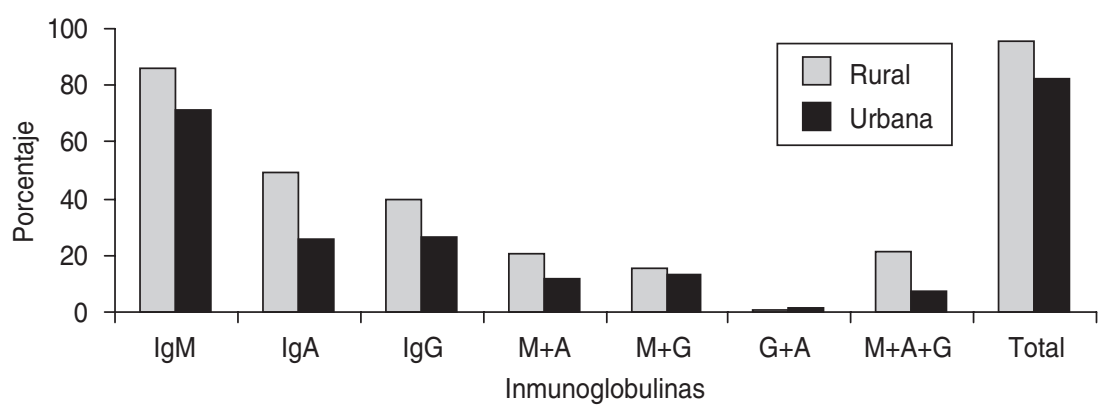

cas de 51-57 kDa y 60-69 kDa. Las inmunoglobulinas $\mathrm{M}$ reaccionaron con fracciones proteínicas cuyo peso molecular osciló entre 8-10 kDa y $105 \mathrm{kDa}$. Sin embargo, los antígenos incluidos en los intervalos de $12-14 \mathrm{kDa}(71,9 \%$ de los sueros), 51-57 kDa $(71,2 \%)$ y 60-69 $\mathrm{kDa}(62,1 \%)$ fueron reconocidos con mayor frecuencia por este isotipo. Con respecto a la inmunoglobulina $\mathrm{A}$, se observó un frecuente reconocimiento de los antígenos incluidos en los intervalos de $42-48 \mathrm{kDa}(57,2 \%), 51-57 \mathrm{kDa}$ (87,3\%), 60-69 kDa $(80,4 \%), 71-78 \mathrm{kDa}$ $(62,7 \%)$ y $80-85 \mathrm{kDa}(54 \%)$. Por último, los anticuerpos IgG reconocieron antígenos con pesos moleculares aproximados de $12-120 \mathrm{kDa}$, y las fracciones reconocidas con mayor frecuencia por este isotipo fueron las de $51-57 \mathrm{kDa}$ $(60,9 \%)$ y de $60-69 \mathrm{kDa}(84 \%)$ (véanse el cuadro 1 y la figura 4).

\section{DISCUSIÓN}

Los resultados de este primer estudio serológico realizado en Colombia muestran una alta seroprevalencia de anticuerpos anti-C. parvum e indican que la criptosporidiosis es endémica y representa un importante problema de salud pública en el país. Este porcentaje de seropositividad $(83,3 \%)$ concuerda con los datos obtenidos en otros estudios llevados a cabo en zonas tropicales, en los que se registraron prevalencias que oscilan entre $60 \mathrm{y}$ $100 \%(9,10)$ frente a valores de $25 \mathrm{a}$ $35 \%$ obtenidos en países industrializados (11-13).

Los estudios sobre la cinética de anticuerpos durante la fase aguda o convaleciente realizados con sueros de individuos en los que se confirmó criptosporidiosis y con sueros de animales natural o experimentalmente infectados han mostrado que, en la mayor parte de los casos, los anticuerpos de las clases $\mathrm{M}$ y A aparecen 5 a 8 días después de la infección, y alcanzan un pico de intensidad entre los días 8 y 15 postinfección, momento en el cual es posible detectar la IgG. Las respuestas de la IgM y la IgA son transitorias y duran solo varias semanas, 
CUADRO 1. Porcentaje de antígenos contra Cryptosporidium parvum reconocidos en los sueros por las inmunoglobulinas $M, A$ y $G$ en sueros de habitantes de la región andina de Colombia, 1996 a 1998

\begin{tabular}{cccc}
\hline $\begin{array}{c}\text { Peso molecular } \\
(\mathrm{kDa})\end{array}$ & $\begin{array}{c}\text { IgM } \\
(n=285)\end{array}$ & $\begin{array}{c}\text { IgA } \\
(n=276)\end{array}$ & $\begin{array}{c}\operatorname{IgG} \\
(n=294)\end{array}$ \\
\hline 120 & - & - & 1,0 \\
105 & 1,0 & 1,4 & 8,2 \\
$97-100$ & 8,4 & 6,9 & 21,4 \\
$90-95$ & 33,0 & 39,5 & 27,6 \\
$80-85$ & 43,2 & $54,0^{\mathrm{a}}$ & 28,6 \\
$71-78$ & 49,1 & $62,7^{\mathrm{a}}$ & 41,8 \\
$60-69$ & $62,1^{\mathrm{a}}$ & $80,4^{\mathrm{a}}$ & $84,0^{\mathrm{a}}$ \\
$51-57$ & $71,2^{\mathrm{a}}$ & $87,3^{\mathrm{a}}$ & $60,9^{\mathrm{a}}$ \\
$42-48$ & 22,5 & $57,2^{\mathrm{a}}$ & 41,1 \\
$37-39$ & 7,0 & 36,2 & 32,3 \\
$32-34$ & 7,0 & 39,1 & 33,7 \\
$26-28$ & 3,8 & 19,6 & 16,0 \\
$23-25$ & 6,0 & 39,1 & 25,2 \\
$20-22$ & 21,4 & 27,9 & 32,6 \\
$15-18$ & 8,8 & 26,1 & 19,0 \\
$12-14$ & $71,9^{\mathrm{a}}$ & 9,4 & 36,7 \\
$8-10$ & 0,7 & 0,7 & - \\
\hline
\end{tabular}

n: número de muestras séricas.

a Antígenos reconocidos con mayor frecuencia por la inmunoglobulina indicada.

mientras que la respuesta de la $\operatorname{IgG}$ es más persistente y puede permanecer durante meses o incluso años (14). En

nuestro trabajo, la prevalencia de IgM detectada $(72,2 \%)$ probablemente refleja que la mayoría de los individuos

FIGURA 4. Reconocimiento de antígenos de Cryptosporidium parvum por los sueros de individuos de la región andina de Colombia, 1996 a 1998

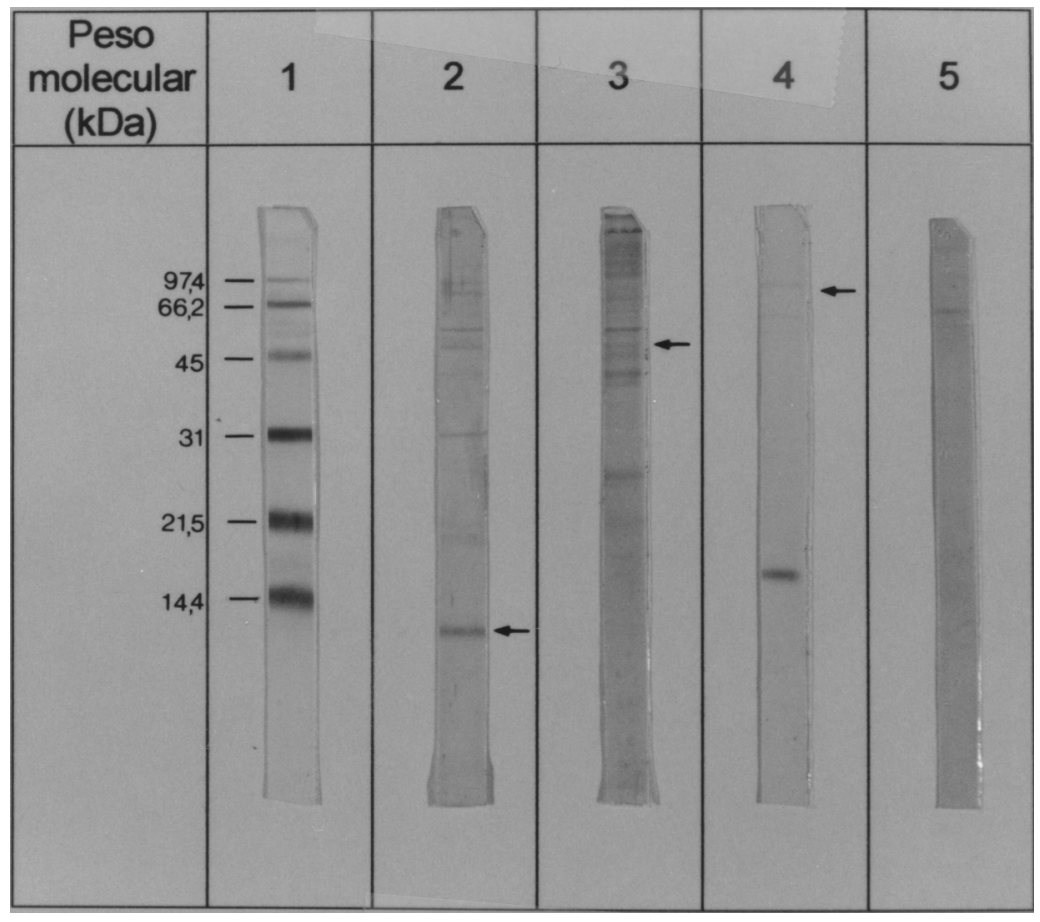

Línea 1. Patrón de peso molecular; Líneas 2, 3 y 4. Antígenos reconocidos por lgM, IgA e lgG séricas, respectivamente; Línea 5. Suero de un individuo control con coprología y serología negativas a C. parvum. Las flechas indican el principal grupo de antígenos reconocidos por cada isotipo. tenían infecciones recientes. Cabe notar que gran parte de las personas seropositivas a la IgM pertenecían al grupo de menor edad, el cual también presentó bajos porcentajes de IgG (22\%). A este respecto, Casemore (15) sugiere que la respuesta de la IgG es leve en las infecciones primarias.

Por otra parte, los elevados porcentajes de seropositividad a la IgM también podrían reflejar una exposición continua al parásito en ambientes contaminados, con el consiguiente reestímulo antigénico, o bien una respuesta más persistente de la esperada, como sugieren Ungar et al. (10). Una explicación similar podría aplicarse a la prevalencia $(27,7 \%)$ de IgA obtenida. En estudios previos, las concentraciones específicas de $\operatorname{IgA}$ se detectaron tanto en muestras séricas humanas como en las de animales natural o experimentalmente infectados. Sin embargo, mientras que en terneros naturalmente infectados la IgA sérica alcanza un máximo que dura por lo menos 3 meses (16), en corderos infectados experimentalmente, Hill et al. (17) observaron un rápido aumento y luego una caída de las concentraciones en el suero que coincidía con el fin de la excreción oocística. Esta discrepancia de resultados puede deberse a las estrictas medidas higiénicas en las que se llevó a cabo este último trabajo, las cuales reducen la exposición al parásito, mientras que los ambientes contaminados provocan una continua estimulación antigénica.

La seropositividad a IgG detectada en la población muestral $(27,6 \%)$ sugiere que los individuos analizados han estado al menos alguna vez en contacto con el parásito. Este porcentaje contrasta significativamente con los hallados en otros estudios serológicos realizados en América Latina. Ungar et al. (10) comprobaron que 64\% de los niños y adultos de una población urbana del Perú y también $64 \%$ de una población infantil seleccionada al azar en zonas marginales urbanas de Venezuela fueron seropositivos a la IgG. La variación en los métodos de muestreo de las poblaciones y las diferencias en los niveles de exposición a 
animales y en las condiciones higiénicosanitarias podrían ayudar a explicar las discrepancias en esos datos (13).

Por otra parte, hemos observado que existe una seroprevalencia aun mayor en la población femenina, no solo en los resultados de la población muestral sino en lo que respecta al isotipo $\mathrm{M}$ y su coexistencia con los isotipos A y G. Este patrón serológico podría sugerir que las mujeres tienen mayores oportunidades de reinfección, lo cual estaría justificado por su comportamiento no solo educacional, sino también ocupacional, ya que esta es la población que habitualmente tiene más contacto con los niños, uno de los grupos de alto riesgo de padecer la infección (2). A pesar de que se ha comprobado que las hormonas esteroideas pueden afectar a la respuesta inmunitaria aumentando los niveles circulantes de IgM, IgA e IgG en las mujeres (18), no creemos, apoyándonos en el criterio utilizado para establecer el valor de decisión de la técnica de ELISA empleada, que esta circunstancia influyera en los valores de seroprevalencia obtenidos.

La susceptibilidad a la infección relacionada con la edad (14) se ve incrementada en aquellas zonas donde las condiciones higiénicosanitarias son deficientes y la desnutrición, junto con infecciones concomitantes, compromete aun más el sistema inmunitario de la población infantil. En nuestro estudio, se observaron los más altos porcentajes de seropositividad en los grupos de 0 a 14 años y de 15 a 30 años. Las seroprevalencias de la $\operatorname{IgM}$, que suelen descender con la edad, fueron mayores en los niños, lo que sugiere una intensa exposición de esa población a C. parvum. Este resultado es el que cabría esperar, ya que datos no publicados de nuestro laboratorio muestran una prevalencia de criptosporidiosis de $4,3 \%$ en niños de la ciudad de Santa Fe de Bogotá (19). Se han encontrado valores similares en niños de otras ciudades colombianas: $4 \%$ en Medellín y 5,1\% en Cali (20).

Por el contrario, los valores de la IgA y la IgG suelen aumentar con la edad, pero en este estudio los porcen- tajes de seropositividad a la IgG fueron similares en los grupos de 15 a 30 años y los mayores de 30 . Si se tienen en cuenta la cinética de los anticuerpos durante el curso de una infección por Cryptosporidium, la resistencia relacionada con la edad y los patrones de seropositividad a la IgM, la IgA y la IgG -de las cuales la primera disminuye y las dos últimas aumentan con la edad de los individuos analizados-, podría sugerirse un papel protector de los isotipos A y G frente a la infección.

Generalmente, la población del medio rural suramericano presenta niveles socioeconómicos bajos, lo que implica deficientes condiciones higiénicosanitarias caracterizadas por la ausencia de infraestructura urbanística y la estrecha convivencia con animales que sirven como fuente de infección. A esto se suma el importante papel que desempeña el agua en la epidemiología de la criptosporidiosis. Teniendo en cuenta este aspecto, los resultados obtenidos tanto en la zona rural como en la urbana se justifican en parte por la contaminación hídrica, ya que las autoridades sanitarias con frecuencia recomiendan hervir el agua destinada al consumo con el fin de prevenir infecciones entéricas. Además, el racionamiento del agua durante ciertos períodos lleva a algunos grupos de población a usar abastecimientos de agua no controlados.

Por otra parte, los estudios de inmunoelectrotransferencia revelaron una decidida heterogeneidad en los patrones de reconocimiento antigénico. Sin embargo, es difícil comparar los resultados obtenidos en distintos estudios debido a variaciones en las condiciones experimentales y a diferentes estimaciones de los pesos moleculares según los marcadores empleados (21).

El frecuente reconocimiento por parte de las inmunoglobulinas M, A y $\mathrm{G}$ de los antígenos de peso molecular aproximado entre 51-69 kDa nos induce a pensar que estos presentan cierto carácter inmunodominante. $\mathrm{Al}$ gunos de ellos podrían corresponder al antígeno de 45,5-51 kDa detectado en la superficie de los esporozoitos por
Nina et al. (22). El grupo de Tilley et al. (23) también notó la presencia de dos glucoproteínas en la superficie de los esporozoitos: una de 14,5-16,5 kDa y otra de $15 \mathrm{kDa}$ reconocida por el calostro bovino hiperinmune. En el presente estudio, el frecuente reconocimiento por la $\operatorname{IgM}$ de la fracción proteínica con peso molecular aproximado de 12-14 kDa nos hace pensar que posiblemente se trate de las glucoproteínas anteriormente comentadas. Esto explicaría, en parte, los altos valores de seroprevalencia de la IgM detectados en la población analizada.

Por otra parte, el polipéptido de 47 $\mathrm{kDa}$ reconocido por un anticuerpo monoclonal y considerado como un antígeno inmunodominante por $\mathrm{McDo}-$ nald et al. (24), puede corresponder a la fracción de 42-48 kDa reconocida por la IgA. En otro estudio (25) se ha descrito el reconocimiento de esta fracción por $43 \%$ de los sueros de bovinos adultos asintomáticos eliminadores de oocistos y seropositivos a la IgG.

En suma, los resultados preliminares de este estudio serológico evidencian altos niveles de exposición a Cryptosporidium entre los habitantes de la región andina colombiana. Se recomienda, por lo tanto, que los prestadores de salud tengan en cuenta un posible diagnóstico de criptosporidiosis al tratar los casos de enfermedad diarreica aguda en esa zona.

Agradecimiento. Los autores agradecen el suministro de muestras séricas a la doctora Margarita Ronderos Torres, Directora de la Oficina de Epidemiología del Ministerio de Salud de Colombia, al doctor Iván Darío Vélez, Director del Programa de Estudio y Control de Enfermedades Tropicales de la Universidad de Antioquia y a los doctores Mario Isaza Ruget, Afranio Veloza, María Victoria Parra, Johana Moreno y Claudia Osorio, de la Clínica Reina Sofía de Santa Fe de Bogotá. Se agradece asimismo a la Agencia Española de Cooperación Internacional (ICI-AECI) el haber concedido una beca doctoral a Claudia Vergara. 


\section{REFERENCIAS}

1. Scott CA, Smith HH, Mtambo MMA, Gibs HA. An epidemiological study of Cryptosporidium parvum in two herds of adult beef cattle. Vet Parasitol 1995;57:277-288.

2. Fayer R, Speer CA, Dubey JP. The general biology of Cryptosporidium. En: Fayer R, ed. Cryptosporidium and cryptosporidiosis. Boca Raton y Boston: CRC Press; 1997. Pp. 1-43.

3. Leal FJ, Franco G, Sandoval C, Gómez E, Buitrago B, Rodríguez G, et al. Agentes etiológicos de diarrea aguda en Bogotá. Santa Fe de Bogotá: Federación Colombiana de Especialistas en Laboratorio Clínico (FECODEL); 1984. Pp. 5-55.

4. Noreña MI. Geografía física. En: Breviario de Colombia. Santa Fe de Bogotá: Panamericana Editorial Ltda; 1997. Pp. 115-159.

5. Lorenzo MJ, Ares Mazás E, Villacorta Martínez de Maturana I. Detection of oocysts and IgG antibodies to Cryptosporidium parvum in asymptomatic adult cattle. Vet Parasitol 1993:47:9-15.

6. Markwell K, Haas M, Bieber LL, Tolbert NE. A modification of the Lowry procedure to simplify protein determination in membrane and lipoprotein samples. Ann Biochem 1978; 87:206-210.

7. Lorenzo MJ. Criptosporidiosis. Detección de anticuerpos séricos en poblaciones humana y animal e identificación de proteínas antigénicas de Cryptosporidium parvum: posibles medidas de control [tesis doctoral]. La Coruña (España): Universidad de Santiago de Compostela; 1993.

8. Sokal RR, Rohlf FJ. Two-way analysis of variance. En: Sokal RR, Rohlf FJ, eds. Biometry. New York: WK Freeman and Co; 1995. Pp. 685-793.

9. Current WL. Cryptosporidium parvum: household transmission. Ann Intern Med 1994;120: $518-519$.
10. Ungar BLP, Gilman RH, Lanata CF, PerezSchael I. Seroepidemiology of Cryptosporidium infection in two Latin American populations. J Infect Dis 1988;157:551-556.

11. Casemore DP. The antibody response to Cryptosporidium: development of a serological test and its use in a study of immunologically normal persons. J Infect 1987;14:125-134.

12. Casemore DP. Epidemiological aspects of human cryptosporidiosis. Epidemiol Infect 1990;104:1-28.

13. Ungar BL, Mulligan M, Nutman TB. Serologic evidence of Cryptosporidium infection in US volunteers before and during Peace Corps service in Africa. Arch Intern Med 1989; 149:894-897.

14. O'Donoghue PJ. Cryptosporidium and cryptosporidiosis in man and animals. Int J Parasitol 1995;25:139-195.

15. Casemore DP. The antibody response to Cryptosporidium: development of a serological test and its use in a study of immunological normal persons. J Infect 1987;14:125-134.

16. Peeters JE, Villacorta I, Vanopdenbosch E, Vanderghynest D, Naciri M, Ares Mazás E, et al. Cryptosporidium paroum in calves: Kinetics and immunoblot analysis of specific serum and local antibody response (immunoglobulin $A, G$ and $M$ ) after natural and experimental infections. Infect Immunol 1992;60: 2309-2316.

17. Hill BD, Blewett DA, Dawson AM, Wright S. Analysis of the kinetics, isotype and specificity of serum and coproantibody in lambs infected with Cryptosporidium parvum. Res Vet Sci 1990;48:76-81.

18. Zuk M, McKean KA. Sex differences in parasite infections: patterns and processes. Int J Parasitol 1996;26:1009-1024.

19. Vergara CA. Estudio inmunológico de la criptosporidiosis humana en Colombia (tesis doc- toral). La Coruña: Universidad de Santiago de Compostela; 1999.

20. Vásquez IH, Restrepo M, Botero D. Criptosporidiosis. Santa Fe de Bogotá: Ministerio de Salud, Instituto Nacional de Salud; 1987. (Monografía ${ }^{\circ} 2$ ).

21. Riggs MW. Immunology: host response and development of passive immunotherapy and vaccines. En: Fayer R, ed. Cryptosporidium and cryptosporidiosis. Boca Raton, Boston: CRC Press; 1997. Pp. 130-154.

22. Nina JMS, McDonald V, Deer RMA, Wright SE, Dyson DA, Chiodini PL, et al. Comparative study of the antigenic composition of oocyst isolates of Cryptosporidium parvum from different hosts. Parasite Immunol 1992; 14:227-232.

23. Tilley M, Fayer R, Guidry A, Upton SJ, Blagburn BL. Cryptosporidium parvum (Apicomplexa: Cryptosporidiidae) oocyst and sporozoite antigens recognized by bovine colostral antibodies. Infect Immunol 1990;58:29662971.

24. McDonald V, Deer R, Nina JMS, Wright $S$, Chiodini PL, McAdam J. Characteristics and specificity of hybridoma antibodies against oocyst antigens of Cryptosporidium paroum for man. Parasite Immunol 1991;13:251-259.

25. Lorenzo MJ, Ben B, Mendez F, Villacorta I, Ares Mazás ME. Cryptosporidium parvum oocyst antigens recognized by sera from infected asymptomatic adult cattle. Vet Parasitol 1995;60:17-25.

Manuscrito recibido el 6 de marzo de 2000 y aprobado para publicación el 29 de agosto de 2000.
ABSTRACT

Cryptosporidiosis in the Andean region of Colombia: seroprevalence and antigen recognition
The objective of this study was to investigate, for the first time, the seroprevalence of cryptosporidiosis among urban and rural inhabitants in several departments of the Andean region of Colombia. The antigen recognition of Cryptosporidium parvum was also studied with sera. Between June 1996 and October 19981778 serum samples were collected from people selected through convenience sampling. The detection of anti-C. parvum antibodies (IgM, IgA, and $\operatorname{IgG}$ ) was carried out with enzyme-linked immunosorbent assay, and antigen recognition was done with immunoblotting. A prevalence of $83.3 \%$ was found, and the antibody percentages were $72.2 \%$ for IgM, $27.7 \%$ for $\operatorname{IgA}$, and $27.6 \%$ for IgG. Higher seropositivity percentages were found among women, persons less than 30 years old, and residents of rural areas. IgM seroprevalence decreased with age, while IgG and IgA seroprevalences increased with age. These three immunoglobulin isotypes most frequently recognized the antigens from 51 to $69 \mathrm{kDa}$, which can be considered immunodominant. Of note was the immunoreactivity of IgM and IgA to protein fractions from 12 to $14 \mathrm{kDa}$ and from 42 to $48 \mathrm{kDa}$, respectively, which could indicate exposure to the parasite. These results indicate that cryptosporidiosis is endemic in the Andean region of Colombia, and that it is possible to attribute many cases of diarrheal syndrome to C. parvum. 